\title{
Hydrology and water resources in Caspian Sea
}

\author{
Kourosh Haddadi Moghaddam \\ International Sturgeon Research Institute (ISRI), P.O. Box 41635-3464, Rasht, Iran \\ Correspondence to: Kourosh Haddadi Moghaddam (khkhmoghadam@gmail.com) \\ Published: 17 October 2016
}

\begin{abstract}
Precipitation is the main driver of the water balance variability of the water over space and time, and changes in precipitation have very important implications for hydrology and water resources. Variations in precipitation over daily, seasonal, annual, and decadal time scales influence hydrological variability over time in a catchment. Flood frequency is affected by changes in the year-to-year variability in precipitation and by changes in short-term rainfall properties. Desiccation of the Caspian Sea is one of the world's most serious ecosystem catastrophes. The Persian Sturgeon (Acipenser persicus) caught under $10 \mathrm{~m}$ depth using bottom trawl net by research vessel during winter 2012, summer and winter 2013 and spring 2014 in east, central and west of southern parts of Caspian Sea, then, their diets were investigated. During 136 trawling in the aimed seasons, Persian sturgeon with 1 to 2 years old and $179.67 \times 0.2 \mathrm{~g}$ (body weight) and $29.97 \pm 0.4 \mathrm{~cm}$ (Total length) captured. Examination of stomach contents in the sturgeon specimens revealed that the food spectrum was composed of bony fishes (Neogobius sp., Atherina sp. and Clupeonella delicatula), invertebrates belonging to the family Ampharetidae polychaeta worms including (Hypanai sp. and Nereis diversicolor), various crustaceans (Gammarus sp. and Paramysis sp.). Investigation on stomach contents of sturgeon Acipenser persicus caught under $10 \mathrm{~m}$ depth in 2012 to 2013 surveys showed that there is significant difference in the consumed food. The most food diversity have been observed in winter 2013, also Polychaeta is the primary consumed food and crustacean is the secondary one $(P>0.05)$, no new types of food (such as bony fishes or benthics) have been observed on food chain of Acipenser persicus and shows no significant difference $(P>0.05)$.
\end{abstract}

\section{Introduction}

Prey abundance, feeding and food habits are important issues for both effective Caspian Sea fisheries management and conservation biology in aquatic environment, so Sturgeons one the most important and valuable fishes in the world and Caspian Sea is one of their most important habitat's which $90 \%$ of total world Caviar belongs to it (Ivanov et al., 1999). In recent years sturgeon stock and catch has been decreased in their most important habitats (Pourkazemi, 1996; Ivanov et al., 1999; Moghim et al., 2006). Biological and feeding factors have great influence an sturgeon catch to determine these factors, we should investigate on sturgeon feeding competition and other relations between different habits of fishes in various places and time is of high importance (Moghim et al., 2006) therefore should navigate the previous studies of researchers in this regards. Initial studies carried out on sturgeon feeding in north, middle and south Caspian Sea
(Shorygin, 1937; Salnikov et al., 1975; Begenal, 1978; Moiseev and Filatova, 1988 and Polyaninova and Molodtseva, 2002). During sturgeon stock assessment at southern part of Caspian Sea in 2006 to 2008, diets of Persian sturgeon investigated in different depths and various seasons. Although some studies conducted in Iran up to now, they were cyclical (Kashentseva, 2005; Hashemyan et al., 2005) considering that too ecological changes happened in Caspian Sea (Haddadi Moghaddam et al., 2003; Roohi et al., 2007) the previous studies don't include all dietary information of sturgeon. So, the aims of the study were (i) determine seasonal change on Persian sturgeon (ii) determine more details on sturgeon food composition and identification of food index to better understand Persian sturgeon feeding condition. 
Table 1. Number, seasons and means body weight (BW), total length (TL) and condition factor in Persian Sturgeon (Mean \pm SD).

\begin{tabular}{lllll}
\hline Mean condition factor & Mean Total length $(\mathrm{cm})$ & Mean body weight $(\mathrm{g})$ & Seasons & Number \\
\hline $0.31 \pm 0.01$ & $25.5 \pm 0.43$ & $48.9 \pm 0.6$ & Winter 2012 & 41 \\
$0.75 \pm 0.25$ & $35.07 \pm 0.8$ & $322.64 \pm 0.3$ & Summer 2013 & 20 \\
$0.48 \pm 0.08$ & $25.91 \pm 0.1$ & $294.81 \pm 0.7$ & Winter 2013 & 32 \\
$0.38 \pm 0.07$ & $33.4 \pm 0.4$ & $52.34 \pm 0.3$ & Spring 2014 & 15 \\
\hline
\end{tabular}

\section{Materials and methods}

The study carried out during March, February 2012, March, February 2013, July, August 2013 and April, May 2014. According to the area of regions, 34 station selected through stratified random sampling design (including 21 stations in east, 5 stations in middle and 8 station in west). The sampled stations were located between $\left(32^{\circ} 2^{\prime} \mathrm{N}, 50^{\circ} 29^{\prime} \mathrm{E}\right.$ and $37^{\circ} 2^{\prime} \mathrm{N}, 53^{\circ} 4^{\prime} \mathrm{E}$ ). Trawling conducted in each trawling, GPS and map with scale $(1,100000)$ used to determine swept distance and geographical conditions of stations. Also bottom trawl (trawl with $9 \mathrm{~m}$ upper rope) and research vessel (250 hsp) were applied in this regard.

During days for $30 \mathrm{~min}(07.00-16.00)$ in each station and the speed was 25 to 3 Knots along the coast .After catching and measuring of mean total length and body weight, the digestive system of samples removed (Tavakoli et al., 2007) In order to remove the digestive tract, an anal incision created along the middle ventral line up to gill. So, the digestive system removed completely from ventral region (Chugunova, 1963).

Fish diets were determined from stomach contents and the ingested food evaluated by enumeration (Biswas, 1993). The manual for Caspian Sea invertebrate identification key applied for identifying primary and secondary foods in stomach content (Pryshtin et al., 1988). For sturgeon diet assessment, prey items were taxonomically classified and four indices the prey occurrence index $F(\%)$, the prey frequency index Cn (\%), gastro somatic index GSI (\%) and condition factor (CF), were calculated as follows:

$-F(\%)=100 \times\left(N_{\mathrm{p}} / N_{\mathrm{i}}\right)$ where

- $N_{\mathrm{p}}=$ the number of stomachs with a specific prey

- $N_{\mathrm{i}}=$ the total number of non-empty stomachs. Values of $(F>50 \%)$ indicate main prey;

$-10 \%<F<50 \%$, secondary food items; and $F<10 \%$, occasional prey and

$-\mathrm{Cn}(\%)=100 \times\left(N_{\mathrm{i}} / N_{\mathrm{p}}\right)$

$-N_{\mathrm{i}}=$ is the number of the prey item in all nonempty stomachs

- $N_{\mathrm{p}}=$ the total number of food items in all stomachs in a sample
- $\operatorname{GSI}(\%)=100 \times\left(W_{\mathrm{s}} / W_{\mathrm{c}}\right)$

$-W_{\mathrm{s}}=$ weight of stomach

- $W_{\mathrm{c}}=$ weight of carcass $(\mathrm{g})$

$-\mathrm{CF}=\mathrm{W} / \mathrm{TL} 3$

- $W=$ weight $(\mathrm{g})$

- TL $=$ total length $(\mathrm{cm})$ (Euzen, 1987; Saborowski and Buchholz, 1996).

\section{Results}

The diet of megrim is based on benthic, teleosts and bottom, Crustacea and polychaeta. In this study different foods observed in Persian sturgeon stomach including various teleosts such as Neogobious sp., Atherina sp., Clupeonella cultriventris and benthic invertebrates like Ampharitidae (Hypania sp. and Hypaniolla sp.) Nereis diversicolor, Crustacean (Paramysis sp. and Gammarus sp.). In this case 115 immature Persian Sturgeons in 1 to 2 years old captured for feeding examination $90 \%$ of caught sturgeon had food in stomach. comparative study of condition factor in sturgeon caught under $10 \mathrm{~m}$ depth showed the highest condition factor in eastern region $(0.75 \pm 0.25)$ in summer 2013 and the lowest one $(0.26 \pm 0.13)$ in western region of Southern part of Caspian Sea in spring. The results showed no significant differences in condition factor of Persian sturgeon $(P>0.05)$ (Table 1).

GSI comparison in Persian sturgeon during different seasons showed that the mean GSI of Persian sturgeon was highest in winter $2013(109.6 \pm 14.7)$ and lowest $(51.83 \pm 3.8)$ in summer 2013. The results showed no significant difference in GSI in various regions and seasons $(P>0.05)$. Investigation of food frequency percent showed that Persian sturgeon used crustacean as basic food in winter 2012, but in order seasons consumed teleostes as secondary food. Statistical results indicate that there is not significant difference in the foods consumed in different seasons and regions $(P>0.05)$ (Table 2).

\section{Discussion}

Coastal zone is important nursery habitats for many fishes where they can feed upon a concentrated food supply. Study 
Table 2. Prey frequency percent in Persian Sturgeon.

\begin{tabular}{lll}
\hline Seasons & Mean food (\%) & Secondary food (\%) \\
\hline Winter 2012 & Ampharitidae (80\%) & Crustacea (20\%) \\
Summer 2013 & Ampharitidae (70\%) & Gobiidae (80\%) \\
Winter 2013 & Ampharitidae (85\%) & (Gobiidae) $(15 \%)$ \\
Spring 2014 & Ampharitidae (50\%) & (Gobiidae (25\%), \\
& & Atherindiae (25\%)) \\
\hline
\end{tabular}

on frequency and type of consumed prey in Persian sturgeon shows no regular pattern in their feeding behaviour under $10 \mathrm{~m}$ depth and Ampharitidae is their primary food. This could be due to unavailability of their food resources and factors like depth, temperature, type of bed and organic material rate. Teleosts consist the basic parts of food consumed by younger fishes (Hashemyan et al., 2005; Mirzajani et al., 2003; Holchick, 1989). But in lower ages considering the depth and environment geographical, conditions, polychaeta consumed by sturgeon. Examination of feeding intensity during recent surveys do not show any type of new food, but the rate and percent of ingested food has been changed and increased during warm seasons. Although factors such as type of bed, organic material rate and physico-chemical conditions can influence on feeding variety in aquatics (Holchick, 1989; Tavakoli et al., 2007; Gegadeesan and Ayyakkannu, 1992; Waldman, 1995). Basic changes occurred in ecological condition of Caspian Sea, which is due to increase in Caspian Sea water level up to $2.2 \mathrm{~m}$ from 1995 and elevation of oxygen level because entering urban and industrial pollution that leads to slugging of bed. These factors caused to specialization of food for some species and more large preys such as various species of teleosts observed in sturgeon stomach contents (Salnikov et al., 1975). Regarding these changes and new ecological condition of Caspian Sea, The results of study don't indicate any new feeding condition for Persian sturgeon. According to studies carried out under $10 \mathrm{~m}$ depth in east, middle and west of southern part in Caspian Sea (Gasemove, 1994) and considering the gradual warming of Caspian Sea water, it was determined that Sturgeon like to use larger preys which influence on the SI and condition factor of one's caught in warm seasons. Teleosts and benthic diversity become warmer seasons of year. Factors such as food frequency in region, food resources and population have the most influence on feeding rate and condition factor in these fishes (Nikolskii, 1963). Studies conducted on SI in 300 Persian sturgeon in eastern, northwest and south parts of Caspian Sea (Salnikov et al., 1975; Zolotarev et al., 1996) showed that SI was higher when Sturgeon consumed teleosts. The changes may be due to competition for using different types of food, sea waves and type of bed that fish inhabited (Graber, 1990; Kostyuchenko, 1994; Chechun, 1998). Study on variety in winter 2013 and spring 2014 is more than other seasons, which may be due to change in south- ern parts of Caspian Sea showed similar results by Cortest and Graber (1990). These modifications reflected changes in the availability of prey which influenced fish diet composition and were probably related to the loss of biodiversity in the Black Sea benthic communities which became dominated by some opportunistic species like polychaetes by Gomoiu et al. (2004).

\section{Data availability}

Analyses of Variance (ANOVA) were performed using the STATISTICA 6.1 program applied for data availability. The results identified by_SD and seasonal changes in stom ach content of Persian sturgeon determined by relative frequency. All statistical analyses were carried SAS version 9.0 software (SAS Institute, inc., USA).

Acknowledgements. This study is part of a project entitled "sturgeon stock assessment in southern parts of Caspian Sea" that was conducted with financial support of Iranian Fishes Research Organization (IFRO) at International Sturgeon Research Institute (ISRI). We would like to thank all the colleagues who helped and supported us in obtaining Persian sturgeon from Caspian Sea with the grant agreement number: 48/689.

\section{References}

Begenal, G.: Methods for assessment for fish production in freshwater, Blackwell science public, UK, 190-194, 1978.

Biswas, S. P.: Manual of Methods in Fish Biology, South Asian Publication, New Delhi, India, 89, 23-25, 1993.

Cortest, E. and Graber, S. H.: Diet and feeding habits and estimates of daily ration of young, Negaprionbrerirostris (Poey), CopelaBul, UK, 4, 204-218, 1990.

Chechun, T. Ya.: Nutrition of the Acipenseridae of the Sea of Azov under Present Conditions, J. Appl. Ichthyol., 38, 155-158, 1998.

Chugunova, N. I.: Age and Growth Studies in Fish, Biol. Bul., 7, 201-210, 1963.

Euzen, O.: Food Habits and Diet Comparison of Some Fish of Kuwait, Biol. Bull., 58, 11-20, 1987.

Gegadeesan, P. and Ayyakkannu, K.: Seasonal variation of benthic fauna in marine zone of Coleroon estuary inshore water, southeast coast of India, Mar. Sci., 15, 223-229, 1992.

Gasemove, F.: Animals and biotic productions of Caspian Sea, Iranian fisheries publication, Iran, 450-455, 1994.

Gomoiu, M. T., Secrieru, D., Paraschiv, G., Opreanu, P., and Puschiaza, D.: Someremarks on the ecological state of benthic populations recorded during the IAEA, Mar. Geol., 9, 12-20, 2004.

Haddadi Moghaddam, K., Parandavar, H., Pajand, Z., Khoshghalb, M. B., Chubian, F., and Jooshideh, H.: Study on feeding habits of sturgeons in the Caspian Sea up to $10 \mathrm{~m}$ depth (Guilan-Province), Iranian fisheries Research Organization publication, Iran, 69-73, 2003.

Hashemyan, A., Khoshbavar, H. A., Rostami, R., and Taleshian, H.: A comparative analysis of feeding habits of sturgeon fish in shallow coastal waters of Mazandaran and Golestan provinces, south Caspian Sea, J. Fisheries Sci., 14, 157-166, 2005. 
Holchick, M.: The fresh water fishes of European. Iranian fisheries Research publication, Iran, 401-422, 1989.

Ivanov, V. P., Vlasenko, A. D., Khodorevskaya, R. P., and Raspopov, V. M.: Contemporary status of Caspian sturgeon (Acipenseridae) stock and its conservation, J. Appl. Ichthyol., 15, 103-105, 1999.

Kostyuchenko, V. A.: Biology and state of fishing of the Sea of Azov Sturgeon's, J. Appl. Ichthyol., 21, 174-187, 1994.

Kashentseva, L. N.: The status of feeding of stellate Sturgeon population in the Caspian Sea, status of commercial species stock in the Caspian Sea and their management, J. Great Lake Res., 4, 23-35, 2005.

Mirzajani, A. R., Yosefzad, E., Sayadrahim, M., and Abdolmaleki, S. H.: Investigation onmeiofauna and substrate characteristic in the southern Caspian Sea, J. Fisheries Sci., 11, 98-107, 2003.

Moghim, M., Parafkandeh, F., Tavakoli, M., and Behruz Khoshghalb, M.: Investigation biological and statistical on sturgeon fish in 2001-2003, Iranian fisheries Research Organization publication, Iran, 61-65, 2006.

Moiseev, P. A. and Filatova, Z. A.: Animals and Bioproductivity of the Caspian Sea, Nauka publication Moscow, 105-114, 1988.

Nikolskii, G. V.: The Ecology of Fishes, Cold spring Harbor, New York, 340-345, 1963.

Polyaninova, A. A., and Molodtseva, A. I.: The benthos sturgeon feeding relationship for the Caspian Sea, J. Ichthyol., 38, 151157, 2002.

Pourkazemi, M.: Caspian Sea sturgeon conversation and fisheries past, present and future, J. Appl. Ichthyol., 22, 1-4, 1996.

Pryshtin, Y. A., Wingraduva, V. N., Kundakuva, V., Kuna, M. C., and Vastakhuva, A. V.: Atlas of invertebrates Caspian Sea, Iranian fisheries Research Organization publication, Tehran, Iran, $345,1988$.
Roohi, A., Naderi, M. F., Vahedi, M., Qasemi, F., Roshantabari, F., Parafkande, B., Hasanzadekiabi, and Shiganova, T.: Strategy of Mnemoiopsis leidyi combating in the Caspian Sea, Iranian fisheries Research Organization publication, Iran, 30-78, 2007.

Saborowski, R. and Buchholz, F.: Annual changes in the nutritive state of North-Sea, J. Fish Biol., 49, 173-194, 1996.

Salnikov, N. E., Kukuradze, A. M., and Kirilyuk, M. M.: Prospects for Sturgeon Culture in the Northwestern Black Sea under Conditions of Complex Use of Water Resources, J. Appl. Ichthyol., 8, 87-94, 1975.

Shorygin, A. A.: Standard methods for water and wastewater, J. Fish. Biol., 5, 74-85, 1937.

Tavakoli, M., Jooshideh, H., Fadaeei, B., Keymaram, B., Parafkandeh, M., Moghim, M., Bahmani, H., Parandavar, Z., Pajand, K., HaddadiMoghaddam, F., Chubian, D., Kor, A., Halajian, F., Chakmeduze, S., Hasanzadeh, H., Taleshian, and Abassi, K.: Stock assessment of sturgeon fishes in the Southern part of Caspian Sea (Iranian water), Iranian fisheries Research Organization publication, Iran, 136-153, 2007.

Waldman, J. R.: Sturgeon and paddle fish Convergence of Biology, politics and greed, J. Fish. Biol., 20, 20-21, 1995.

Zolotarev, P. N., Shlyakhov, V. A., and Akselev, O. I.: Food Supply and Feeding of the Russian Sturgeon Acipensergueldenstaedtii and the Starred Sturgeon Acipenserstellatus in the North western Black Sea under Modern Ecological Conditions, J. Appl. Ichthyol., 36, 357-362, 1996. 